Published online 05 24, 2021

ISSN 2763-5392

\title{
Sexual abuse in men and the repercussion of the concept of masculinity on affective development
}

\author{
Igor Gomes dos Santos ${ }^{1 *}$; Fabiane Gonçalves ${ }^{2}$
}

1 Graduated in Psychology from the Faculty of Human Sciences of Olinda-FACHO and Post-graduated in Interventional Actions in Clinical Psychology also by FACHO. He has experience in clinical psychology mainly in the care of young adults.

2 Master in Cognitive Psychology from the Federal University of Pernambuco. She is an Adjunct Professor in the Department of Psychology at the Faculty of Human Sciences of Olinda. He has experience in Psychology, with emphasis on Cognitive and Clinical Psychology, working mainly on the following topics: Language, Body, Gender, Development and Culture

E-mail adresses: Igds94@gmail.com (Igor Gomes dos Santos), fabianemsg@facho.br (Fabiane Mônica Gonçalves),

${ }^{*}$ Corresponding author

\section{To cite this article:}

Santos, I.G.; Gonçalves, F.M. Sexual abuse in men and the repercussion of the concept of masculinity on affective development. International Journal of Sciences. Vol. 1, No. 3, 2021, pp. 75-80. ISSN 2763-5392

Received: 05 08, 2021; Accepted: 05 10, 2021; Published: 05 24, 2021

\begin{abstract}
This study aims to understand how the concept of masculinity can have repercussions on the discourse of men who are victims of child sexual abuse. To this end, the concept of masculinity in society is questioned in research and how these restricted convictions, which often function as a kind of manual of masculinity, imply in the subject's conduct, and how often this belief in a specific way of being a man ends up implicated from an early age that man needs to give up his feelings and that, some of the most natural acts such as crying should always be censored, making boys men with serious difficulties in demonstrating and recognizing their feelings. Next is a study on what would be the implications of these concepts of masculinity strongly related to sexuality and strength, when this man is deprived of this place through sexual violence, making a connection with the culture of rape that encourages boys to think and wish to start their sex life from an early age, bringing a different point of view from common sense, who denies the possibility that a boy may be abused by a woman and that practices such as taking boys to start sexually in brothels should also be seen as sexual violence. Finally, it is addressed how this concept of masculinity also affects the search for help, in addition to this social is present in the subject's discourse in the therapeutic setting and how it is necessary for the professional to be aware of such implications to propose a properly welcoming and judgment-free environment. To address the proposed theme, the article was constructed from a narrative bibliographic review.
\end{abstract}

Keywords: Masculinity. Sexual violence. Chauvinism.

\section{Introduction}

Man, in society has held a very well-determined place and functions since forever, but very little is discussed about this ancient concept of masculinity, often based on structural machismo that hurts all those who do not meet all the requirements. Apparently, it is difficult for man to question and debate masculinity, taking into account the low number of materials written by men, especially in the daily lives of these who do not even want to be able to talk about it from father to son. It is common sense to think that crying and expressing their feelings are not man's things, because it is very common to witness censorship to any manifestation of feelings that are compared to that of a woman, while being encouraged to at least already think about sex from an early age.

So, it is very common to see boys resonating on these pillars cited as a way of recognizing themselves as men, but it is important to ask questions about how these concepts imply in the life of a man who carries the scar of sexual violence that occurred at the time of his childhood. Like this guy who learns from an early age that he needs to be unwavering and sexually active, he is wounded in a time of vulnerability, precisely by a sexual act.

Sexual violence against boys is more common than one thinks, with the main reason, the shame that boys feel of exposing such humiliating and degrading violence to a subject with so many social crossings, who often prefers to keep the secret as a way to survive in the male environment without suffering from the judgment and intolerance of other men. Although these concepts still have a great influence on men's lives in general, changes in social paradigms are an ally to overthrow machismo that makes it difficult for men to express themselves and seek help. Therefore, it is necessary 
that the professional behaves as such and is aware of such problems that may slow the therapeutic process, and it is necessary to respect the patient's time in addition to granting the patient a place of listening and acceptance free of judgments.

This study aims to understand how the concept of masculinity can have repercussions on the discourse of men who are victims of child sexual abuse. In this sense, it was necessary in the results and discussions to seek about the concept of masculinity that crosses man in society; understand the social implications of sexual abuse in men in childhood and finally discuss the repercussion of the concept of masculinity in the clinical discourse of men victims of sexual abuse in childhood.

\section{Methodology}

This is a narrative bibliographic review study, which aimed to gather, evaluate and synthesize studies already carried out on the proposed theme. We searched and analysed works available in the research databases: SCIELO, GOOGLE ACADEMIC, PEPSIC, books from the personal collection, JUSBRASIL and Documentaries of the YouTube and Vimeo platform.

These searches were conducted from October 2020 to January 2021, using the following descriptors: Machismo; Sexual abuse in men; Sexual Violence; Rape culture; Boys, boys. Masculinity; Male and female social roles; Masculinity in the clinic; Role of the psychologist; Psychological and physical damage to boys who have been sexually abused.

Based on the abstract and title, a refinement was performed and articles, books, documentaries and a song that were more consistent with the theme initially proposed were selected. Works that did not portray sexual abuse in men were excluded, since most of them were found publications that referred to sexual abuse in female children. The extracted data were used descriptively to understand and critically evaluate the impacts of sexist culture on the affective development of a man after suffering sexual abuse in childhood.

\section{Results and Discussion}

\subsection{Concept of Masculinity that crosses man in society.}

The concept of masculinity in Western society is much discussed and questioned by various social segments. Some intend to preserve as a value that must be maintained and others promote a resignification of what it is to be a man. It is this type of clash between a supposed fidelity to an old idea of what it is to be a man that the author Muszkat $(2018$, p.7) draws attention to a little debated reflection:

[...] that the male in our culture is as subordinate as the feminine, although this is not recognized as such in the collective imaginary. Both are subjugated to the set of representations of a social imaginary created by groups holding power strong enough to keep them - if not enlarge them.

Muszkat (2018) asks that the male code would be treated superficially and simplistically and questions why it is so rare to see men talking about the topic. The observation extends to the academic environment, which, even for a long time being the only ones responsible for all the theoretical material, still does not hear movement on the part of men to discuss or question this role attributed to them. One wonders whether it is in the interests of men to deal with the issue, or, if there is a fear of going against what would function as such a restricted and well-established primer on how masculinity should be exercised, as if there was a "correct" way of doing so.

It is possible to say that a violent separation of tasks is made in which women are denied rights such as power and independence and man is denied the right to allow himself to suffer and to assume any posture, which may be related to sensitivity or move away from the image of extreme strength and rationality, corroborating what is said by Muszkat (2018), when he says that both man and woman are victims of the strength of this imaginary that oblige them to follow their supposed pre-designated roles.

Naturally, as the family environment is usually the first degree of cultural interaction of an individual, the figure of the father is cited numerous times as the greatest male reference for men during their development even in their adult behavior, one of the data presented in the documentary "The Silence of Men" by Leite e Castro (2019), one in ten men had the opportunity to talk about masculinity with their father.

The patriarch of the family is the main responsible for what men in formation will understand as masculinity, even if, even they have a well-structured idea of what this means, and thus passing on their confusion and ignorance onwards.

In the filming of the documentary cited, there are several reports of decisive experiences in these men's view of what masculinity would be, often based on the suppression of feelings of frailties that may be related to femininity and the encouragement of violent behavior as a way of emphasizing masculinity. This may be a good indication of how the idea of masculinity in force can be directly related to violence in general.

The directors of the documentary (2019) support the relationship of men with violence presenting data and statistics from the Ministry of Health as the fact that: $83 \%$ of deaths by homicide or accident have men as victims, besides that they live on average 7 years less than women. Thus, it is possible to prove how, at the same time, man is the major cause of violence, he is also the greatest victim of violence.

Not by chance the name of the work is: "The silence of men" (2019), because the main problem addressed is the fact of how much is said little about the suffering that man carries, due to an unwelcoming culture, in which the act of talking about anguish and fears, is a cause of humiliation, even if this that humiliates only does so to escape the idea that goes through the same, while, it can be observed in their discourse too, sex is a strong pillar of this widely encouraged male ideal, sometimes even early, it is also possible to see a taboo when it comes to any other facet that departs from the idea of the "sex machine" that every man should be in bed, such as homosexuality.

The psychoanalyst Corbertt (2009) underpins the theory of revulsion at male homosexuality because it presents itself as a form of masculinity structured differently. Braga et al. 
(2018), recalls that the sexual and social structure to which we are submitted in addition to generating conflicts, perpetuate the naturalization and compulsories of heterosexuality. That is, an example forms a violent way to which is treated a man who escapes the standards and a delegitimization of gender. Also, according to Corbett (2009) there would be a (dis)lease when the male homosexual would be being seen as female or as a simulated femininity.

Within this context, there are many implications that cause man, from the beginning of his life, to behave like a gallant or even a sex-hungry predator, provided that the relationship occurs with a woman and that he takes an active role in the relationship.

There are many social implications that reverberate in the constitution of male sexuality, but what would be the consequences of early exposure to sexual practice and what happens when this man in formation is deprived of this active place, usually related to the male and becomes a victim of sexual violence, thus subverting the experience so idealized and desired making it a traumatic event?

\subsection{Social Implications of Sexual Abuse in Men in Childhood.}

In his work Furlan (2011) states that sexual abuse is usually based on a power relationship in which the adult takes advantage of his victim's vulnerability, being in most cases happening indoors by a family member, often in an incestuous relationship. Pfeiffer and Salvagni (2005) bring worrying figures when they point out that, according to the World Health Organization (WHO), sexual abuse against children is one of the biggest public health problems.

Love, sex, affection and humiliation are lived ambiguously, with disrespect for the needs and development of the child. Care, orientation and protection, expectations of roles to be fulfilled by adults are exchanged for attitudes of possession and invasion of the child's and adolescent's body (FERRARI; VECINA, 2002, p. 76-77).

According to what is said by the authors (2002), speaking with emphasis on the violence that occurs within the family, it is possible to say that children and adolescents live in an environment full of stimuli that need to be shielded and protected by the adults who surround him and sexual violence is a form of betrayal of this person who takes advantage of his position of influence on the child to whom he should protect.

In their work, the authors (2002) inform that the main responsible for violence against the minor are the parents, then the stepfather and third, someone outside the family circle. It is possible to observe that this relationship of power of the patriarch towards the family can act as a facilitator for these acts of violence. It is also emphasized the fact that they are victimized by people who take advantage of the affective dependence of the victim within a home and in a context in which abuse is the only time when these children receive something close to an interaction with them that should be their protectors.

According to Ferrari and Vecina (2002) a child suffering some kind of violence can have physical and emotional development seriously impaired, along with a strong difficulty in creating bonds. In some cases, emotional distress can lead to death by suicide. The authors name a strong element that functions as a facilitator and ally of the aggressor: "plot of silence". That in intrafamily violence works as follows: the aggressor (usually the patriarch, being the biological father, grandfather or stepfather) has the silence of the non-aggressor family member, who is usually the person who plays the role of mother to the victim, and also has the silence of the victim himself.

In the case of the victim (2002), questions were raised that generate silence such as: the fear of losing the love of the aggressor agent, which may be stronger in case of abuse suffered by the father figure, the feeling that no one can do anything to prevent violence, fear of having discredited testimony and suffering other people's judgment, fear of being removed from the family, among others.

Pfeiffer and Salvagni (2005) point out as recurring causes for the silence of victims the fact that, in many cases, the sexual aggressor uses physical and moral violence against them, causing them to fear for their lives. The feeling of guilt is also frequent as one of the main reasons for silence, because violence often happens before the child understands what it is about and especially when talking about cases of abuse committed by a family member.

The authors (2005) report that it is common for the abuser to tell the victims that, in fact, all this procedure would be normal between parents and children, which causes this trust allied with innocence to result in a closeness, interpreted by the child as an act of affection that would make it special in the eyes of that family member.

Undoubtedly, sexual violence suffered in childhood, as at any age, brings much pain to the victim, whether boy or girl, however, there are peculiarities related to male suffering, endorsed by a patriarchal and macho culture that crosses man with retrograde teachings that can derail the process of resignification of abuse.

In the documentary Leite e Castro (2019) are presented data that reflect how much the man believes to have to suffer in silence when they claim that on average a victim of abuse takes 20 years to talk about the abuse suffered. It is possible to affirm that the man feels emasculated when mentioning the event, especially taking into account the fact that most of the aggressors are men, even what has been recorded, which can be a determining factor in the fear of the judgment already mentioned.

This fear of exposure and judgment that accompanies the victims is well represented in the documentary by Hohendorff and Rodrigues (2011) "Overcome - Sexual violence against boys" when it presents reports how it is suffered carrying the trauma with it due to the strong feeling of guilt and dread of being considered gay, causing the victim to believe that there is no one reliable to share his anguish by imprisoning the boy in what has been named as "cage of silence"

Sebold (1987) apud Almeida, Penso and Costa (2009) report that the fear of homosexuality supposedly resulting from sexual violence would be the main differential between male and female victims, because, as previously mentioned, men are not allowed to complain about their suffering, leaving only to keep everything to themselves and suffer silence, so 
the authors claim that another difference between cases of sexual violence against boys and girls would be the notification between them, because, in case of abuse against girls, the case receives due attention and resonates much more, however, when a boy is victimized, both the victim himself and the parents to know, take the secret as a way to preserve the boy.

It is very clear the fear that the victims become homosexual and the revolt that brings the idea of an adult man touching a child inappropriately, but also, it is necessary to take into account the cases in which the woman commits the aggression and debate what are the inferences of a sexual act so encouraged and even imposed by a social pressure.

\subsection{Women as Male Child Sex Offenders}

Sexual violence against boys is much less reported and commented than cases involving girls, for the sake of shame and fear of a murder of the reputation of the one who would become a man according to the sexist ideal, but after the event, would have no destiny other than homosexuality, according to the same social point of view. Thus, even less talk of cases in which women are perpetrators of violence

According to the studies of Próton (2019), the preestablished idea that man is always the one who always assumes an active role, while the woman would always be that welcoming figure and caregiver who passes confidence and is very difficult to be considered as someone fit for crime or capable of any act of violence, would be an ally in the case of abusers who take advantage of this idea as a way to obtain the trust of victims, usually male. The woman as an aggressor uses this social context that men are naturally more likely to be considered abusers, and thus, if necessary, use this to discredit it when discovered.

The author (2019) points out among the difficult factors the fact that in cases of abusers women it is also much more common that there are blood ties between them besides the fact that often the abuser practices violence in a subtle way disguised as a form of affection, preventing the child from even understanding what occurred, also the idea that the man since childhood, is seen as an always active and willing to act sexually.

She also discusses the social imaginary as a matter of cultural collections, which is expected of man from an early age that they are always waiting for his sexual initiation. Therefore, one imagines that the victim would actually feel or would have to feel privileged or lucky to find a woman willing to start it in the sex life.

Próton (2019) adds that this idea of common sense often reaches scientific works, presenting concepts in which boys are immune to sexual violence. Within this context, they end up getting in the way a lot, because it is believed that if a boy who goes through this violence, he must have wanted or allowed it to happen.

There is also, the culture of sexual initiation of boys, they are led by the patriarch of the family to lose their virginity to a prostitute as a way to ensure that this becomes a virile man. This custom is quite internalized in male culture to the point of becoming history in a famous song of the 90 s entitled
"Whore in John Pessoa" by the Raimundo's BAND that tells the story of a boy referred to as a "newly teenager" who is taken by two older cousins to have their first sexual relationship as a way to "become" man, or as a way of proving that it would not be the first "fresh" of the family, which can be understood that it would be an unhappiness for their relatives, and that it would possibly be a cause for shame, since, they are crossed by this normative straight culture.

If a boy is touched by a man, studies show that concern about the victim's trauma is left in the background, in the face of fear of homosexuality or fear of being considered gay. If a woman abuses a boy, the same will face numerous questions, because, for a cultural motivation, it is very difficult to conceive the idea that a man could feel used by a woman and yes, that he should feel lucky for the opportunity to "have sex" from an early age. And if a father takes his son to be deflowered by an adult woman, all this violence is treated as a kind of initiation ritual, in which for the boy, there is nothing left but to honor the family name by showing how virile it is.

Although the society and culture in which the inhabit ing stakes in this place of sexual potency and a strong and unwavering figure, this man feels the anguish, which is denied and that even feeling, often does not allow himself to feel. So, it is up to your therapist to manage properly when dealing with such sensitive issues, issues that reverberate in affective development.

\subsection{Repercussion of the Concept of Masculinity in the Clinic and in the Development of the Affective Relationship}

If you come across a demand like this can be shocking, also for the therapist. However, it is necessary to be a point of view of your role as a professional and take into account the necessary points. It is known by Freud's work (1905) translated by Souza (2016) involving hysterical patients who would have undergone a psychic trauma in childhood caused by a seduction of a wicked adult, however, with the advancement of his work, the father of psychoanalysis discovers that in many cases seduction did not actually occur, but rather, it was a "recalque" of the period of the which the patient wishes to seduce and be seduced by a parental figure, but when castration was instituted, it would be more bearable to remember what happened in a passive way.

However, whether it actually occurred or not, seduction should not be the main focus of the analysis, because, regardless of this, the marks that remain on the individual are equally legitimate. In this article, the object of study is the victims of sexual abuse in childhood, male, in which the episode or episodes of abuse actually occurred, and not, the individuals described by Freud. Even if, both, have their equal importance and need for welcoming and deepening studies by the psychology professional.

As mentioned earlier, the man is not accustomed and often cannot accept his condition as a victim, because he would be betraying this kind of male rule, so it is important that the professional who receives him in the therapeutic setting is aware of the delicate situation in which the client may be, so that he/ she knows that he is in a welcoming 
environment and, therefore, should not be replicated by the professional any behavior or judgment based on this culture.

Based on his experience in psychoanalytic clinic, Hefez (2013) presents a very optimistic view of these paradigm changes when observing the interaction among young people, who are apparently gradually getting rid of the old issues that guided the masculinity of the citizen over the years. However, he claims to come across some cases in which he perceives a strong anguish in those men who no longer fit the old concept of how to behave, which on the one hand can be liberating, because today it is possible to get rid of outdated concepts, already mentioned earlier, but at the same time still cannot say what it is to be a man.

In the case of victims of sexual violence, they may present several symptoms that make this adaptation impossible. As has been seen, to the man, before a macho society, it is better accepted that he is an aggressor than a victim, and although often the victim finds in the practice of abuse as an abuser, a way to elaborate the pain of having gone through that trauma, often the victim of violence can carry profound sequelae that lead him to the therapeutic setting.

As can be seen in Lima's work (2012) some of the longterm consequences are sexual dysfunctions. In the case of men, it is very painful to live in a society in which, man is so charged virility, presenting any sexual difficulty. As I have mentioned earlier, in society man is crossed by a culture in which virility would be one of the main pillars and therefore, a recurrent dysfunction of a trauma due to sexual violence can be a motivator for this victim to seek a professional. In this sense, it is possible a link between the abuse and the trauma caused by him as if the abuser had "broken" the victim, distating her from his masculinity.

A great contributor to a Manichean view of masculinity is the so-called "Culture of Rape", in which machismo and misogyny perpetuate this type of violence. It does not mean that all men will be rapists, nor that we could reduce them to mere products of society. What is necessary to understand is that the culture of rape determines behaviors, both of women, who should not go out only at night, drink, wear short clothes, depositing in them the responsibility for the acts of other people on their body. As for men, who in this same culture, teaches them that they should take advantage of any opportunity for sexual rape, as if sexual power were in men and he could perform it against women, and even against other men (SOUSA, 2017).

This culture also affects boys who are encouraged to behave like sexually active men. It is possible to think of the early sexualized environment that a boy has faced since the beginning of his life, since it can be said that encouraging a boy who knows almost nothing or is interested in sex, to behave like a sexual predator, should also be recognized as a form of sexual violence.

Despite the new paradigms that are emerging, the concept of masculinity is still based on a strongly consolidated idea that man cannot demonstrate feelings that can pass on the idea of fragility or sensitivity. However, these changes call upon these men who once occupied well-established places, today they are confused and lost, because they have increasingly begun to question what was previously unquestionable: what it is to be a man and I kind of a man I want or should be.

All these changes and issues can make the process increasingly painful for those who suffered from sexual violence in childhood, since, of course, they already feel devoid of the masculinity that rightly so far. Faced with this masculinity in crisis, men broken by sexual trauma, need to go through a narrow path full of obstacles made of prejudices, yours and others to be able to question and find out how you can exercise your masculinity in the way that suits you.

Despite the confusion that man can face in the face of new paradigms, it is possible to say that the same paradigms that are long holding the man in a tight box, are being broken, which can bring a great advance in the cases of victimized men, because without these taboos and fears, the victim can appropriate his right to seek treatment and feel free to end silence.

In this sense, according to Junior and Ramos (2010) it is necessary that the psychology professional be "free" of purely moralistic questions so that an investigative police dimension is not reinforced, failing to observe and listen to the subject, at risk of fixing him in place only of victim or aggressors, making them only objects of law enforcement.

\section{Conclusions}

Despite all the social privileges that man possesses, it is possible to observe how he can become hostage to the macho stereotype that accompanies him, because only men who follow a very restricted concept of masculinity, is seen as a real man, and any deviation from this concept is liable to intolerance by other men, because even with all the perks, man is allowed only virility, emotional coldness and strength.

Being this virility, one of the main pillars of this male concept, a toxic and abusive posture is often allowed, provided that it still fits within this male ideal and especially if it reinforces them.

Man is able to endure heavy demands for defending what he understands as his masculinity. In cases of sexual abuse, it makes it even more difficult for a man to seek psychological care, because he feels devoid of his masculinity, which means a lot to all who are crossed by this culture, as if the aggressor had withdrawn his right to grow as the man who idealizes to be, because such violence, brings scars and emotional and sometimes physical sequelae, causing the impression that that aggressor had broken his or her manhood.

Knowing all this, the professional needs to take into account the social issues that cross the patient and act in a neutral and empathetic way so that these issues that also cross him do not affect his work, because it is necessary that the individual who already goes over so many prejudices, both social and their own, it becomes necessary to find in the therapeutic setting a welcoming and judgment-free environment.

Society faces new paradigms that challenge these retrograde concepts, and this man who never wanted to allow himself to stop to reflect on masculinity, today he sees himself in this moment of transition, in which some face difficulty to fit in, while feeling freer to be men in the way that suits them. 
And the work of a professional can also assist in this demand.

\section{Acknowledgements}

I thank God first for the strength he has given me to complete this work, even in the midst of so many adversities in which we are living. I thank my family, who supported me so much, even when I thought I couldn't finish it, especially for having had such a great loss, which was my Aunt Edian. So, my victory is also in honor of her.

I also thank my life partner Fernanda Nogueira, who helped me so much, and to friends, that without them my days would not have been lighter. Finally, I thank my advisor Fabiane Gonçalves whom I admire so much, for the patience and exchanges of knowledge that has added so much to me.

\section{References}

[1] ALMEIDA, Tânia Mara Campos de; I THINK, Maria Aparecida; COSTA, Liana Fortunato. MALE CHILD SEXUAL ABUSE: DOES GENDER CONFIGURE SUFFERING AND FATE? Clinic Styles, [s. 1], v. 14, n. 26, p. 46-67, 2009. Available in: http://pepsic.bvsalud.org/pdf/estic/v14n26/04.pdf. Accessed: 17 Nov. 2020.

[2] BRAGA, Iara Falleiros; et al., Family violence against gay and lesbian adolescents and young people: a qualitative study. Revista Brasileira de Enfermagem, [S.L.], v. 71, n. 3, p. 12201227, 2018. FapUNIFESP (SciELO). http://dx.doi.org/10.1590/0034-7167-2017-0307.

[3] BRANDÃO JUNIOR, Pedro Moacyr Chagas; RAMOS, Patricia Lemos. Sexual abuse: what is it about? Contributions of psychoanalysis to the subject's listening. Psic. Clin., Rio de Janiero, v. 22, n. 1, p. 71-84, 2010. Available in: https://www.scielo.br/pdf/pc/v22n1/a05v22n1.pdf. Accessed: 21 Jan. 2021.

[4] CORBETT, Ken. The mystery of homosexuality. J. psicanal. , São Paulo, v. 42, n. 76, p. 159-176, Jun. 2009. Available in: http://pepsic.bvsalud.org/scielo.php?script=sci_arttext\&pid=S 0103-58352009000100011\&lng=pt\&nrm=iso. Accessed: 07 nov. 2020 .

[5] FERRARI, Dalka Chaves Almeida; VECINA, Teresa Cristina Cruz. The end of silence in family violence: theory and practice. São Paulo: Agora, (2002).

[6] FURLAN, Fabiano et al. CHILD SEXUAL VIOLENCE: The ABUSIVE/ABUSED DIALECTIC AND THE COPING SYSTEM. Experiences: Electronic Magazine of Extension of Uri, [s. 1], v. 7, n. 13, p. 198-208, 2011. Available in: http://www2.reitoria.uri.br/ vivencias/Numero_013/artigos/art igos_vivencias_13/n13_22.pdf. Accessed: 16 Nov. 2020.

[7] HEFEZ, Serge (Men on the couch: reports on the male identity crisis: Benvirá, 2013. 217 p.

[8] LIMA, Isabel Vieira Braz; DIOLINA, J. Psychological Consequences of Sexual Abuse in Childhood and Adolescence: an Invisible Wound. Available in: http://www.site.ajes.edu.br/direito/arquivos/20131030201243. pdf. Accessed: 06 Jan. 2021. of Masculinities in the Contemporary World. Sp: Summus Editorial, 2018. 153 p.

[10] The SILENCE OF MEN. Directed by Ian Leite and Luiza de Castro. Coordination of Ismael dos Anjos. [S.I.]: Papodehomem and Pdh Institute, 2019. (60 min.), son., color. Available

in: https://www.youtube.com/watch?v=NRom49UVXCE\&t=281s. Access: 30 Oct. 2020.

[11] PFEIFFEr L, Salvagni EP. Current view of sexual abuse in childhood and adolescence. Jornal de Pediatria, Rio Janeiro, 2005;81(5 Supl) p.197- 204. Available in: https://www.scielo.br/pdf/jped/v81n5s0/v81n5Sa10.pdf. Accessed: 21 jan. 2021.

[12] PROTON, Sara. Sexual abuse of boys: a crime committed by women. 2019. Available in: https://saraproton.jusbrasil.com.br/artigos/739336713/abusosexual-de-meninos-um-crime-praticado-por-mulheres. Accessed: 26 Oct. 2020.

[13] RAIMUNDOS. "Puteiro" in João Pessoa, 1994.

[14] SOUSA, Renata Floriano de. Rape culture: practice and incitement to sexual violence against women. Revista Estudos Feministas, [S.L.], v. 25, n. 1, p. 9-29, Apr. 2017. FapUNIFESP (SciELO). http://dx.doi.org/10.1590/1806-9584.2017v25n1p9. Available in: https://www.scielo.br/scielo.php?script=sci_arttext\&pid=S010 4-026X2017000100009\&lng=pt\&tlng=pt. Accessed: 10 Jan. 2021.

[15] SOUZA, Paulo César de (Trad.). Sigmund Freud: three essays on the theory of sexuality, fragmentary analysis of a hysteria ("the dora case") and other texts (1901-1905). Sp: Companhia das Letras, 2016. $6 \mathrm{v}$.

[16] VON HOHENDORFF, Jean; SANTOS, Samara Silva dos; DELL'AGLIO, Deborah Dalbosco. Case study on the revelation of sexual violence against boys. Clinical Contexts, [s. 1], v. 1, n. 8, p. 46-54, 2015. Available in: http://pepsic.bvsalud.org/pdf/cclin/v8n1/v8n1a06.pdf. Accessed: 17 Nov. 2020. 